\title{
Environmental stress, displacement and the challenge of rights protection
}

\section{Roger Zetter and James Morrissey}

Examination of migration histories and current politics in Kenya, Bangladesh, Vietnam, Ethiopia and Ghana sheds light on how rights are articulated for groups and individuals displaced in a context of environmental stress and climate change. Both migration and rights are sensitive issues in these case-study countries, and the conjunction of the two is especially sensitive.

The existence of a protection gap for environmentally displaced people is surprising given the scope of protection available to other groups of displaced populations in domestic and international law. However, it may make little sense to privilege individuals displaced by the impacts of climate change (or other forms of environmental stress) over other 'involuntary migrants' moving for a variety of reasons who are similarly outside already well-established categories or, conversely, for whom there is established protection apparatus such as the Guiding Principles on Internal Displacement. ${ }^{1}$
Indeed, with the exception of the 2009 African Union Convention for the Protection and Assistance of Internally Displaced Persons in Africa (known as the Kampala Convention), ${ }^{2}$ there are no international legal instruments or norms that deal specifically with the protection of the rights of those whose displacement could be attributed in some way to environmental or climatic factors. Yet the countries of our study have not applied these instruments to the situations of displacement related to environmental change. This article explores why this is so. 


\section{Displacement, protection and rights}

In general terms, protection in relation to people on the move is concerned with safety, security, dignity and reducing vulnerability, as well as securing or safeguarding political, civil, social, economic and cultural rights, including freedom of movement.

Environmental stress in general and climate change in particular potentially impinge on the enjoyment of this wide range of domestic and internationally protected rights. In other words, ensuring rights and protection is part of the wider challenge of managing the consequences of environmental change, and particularly climate change. Given the likely predominance of internal migration, this article focuses on national responses.

In practice, the discourse of rights is frequently reduced to a focus on material rights, at the expense of the much more challenging issue of affording political rights. In material terms, protection may be conceived of in terms of physical assistance to overcome the impact of flooding and shelter provision in resettlement programmes, for example. It is this material representation of rights protection which dominates current thinking in the context of environmental displacement. But the protection of rights may also be conceived of in structural terms, since a process to tackle the structural and systemic inequalities and risks that underlie disaster vulnerabilities and the impacts of environmental stress - such as land rights or access to compensation - is inherently political and thus far more problematic.

The discourse on rights protection among the national agencies addressing environmental change in the five country case-studies has focused on material rights, to the exclusion of the provision of political rights. We suggest that migration histories and current politics shape the way in which migration policy regimes are conceived and framed, and how rights are articulated for those groups and individuals displaced in a context of environmental stress and climate change. Thus, it is through analysing the politics of migration and rights that we can better appreciate why it is that these governments do not, as yet, accord a full range of rights to those who are displaced, or threatened by displacement, in this context.

\section{Kenya}

Questions of migration and population displacement in Kenya are highly politicised as a result of their close relationship with issues around land, unequal access and social grievances. These issues can be traced back to the colonial period and its practices of eviction (i.e. forced migration) and unequal development. They underlie the violence and conflict-induced displacement following elections in 1992, 1997 and 2007. And it is a legacy that conditions how displacement in the specific context of climate change and environmental stress is addressed.

The Kenyan Constitution provides some level of rights protection for displaced persons. However, Kenya has struggled to incorporate the rights-based norms of the Guiding Principles and the more recently proposed national guidelines on IDPs into its national legal or normative frameworks. The adoption of a comprehensive framework on IDPs, as proposed in the National Policy initiative and underscored by the Kampala Convention, could be a milestone in rights protection in Kenya and could be extended to environmentally displaced people. The domestic proposals, however, concentrate on addressing the immediate displacement impacts of recent political unrest, the peaceful reconstruction and rehabilitation of the country, and natural disasters.

The focus on disasters simultaneously ignores the impacts of slow-onset environmental stresses and frames the issue of displacement in terms of material deprivation. The latter allows for a focus on tackling material rights, such as food assistance, while leaving the crucial issue of political rights unaddressed. This is thought to be driven, in part, by the fact that addressing such concerns would require the resolution of the underlying issues over asymmetries of power and historical grievances. In such a 
context concerns about the rights of those susceptible to the displacement effects of climate change and environmental stress remain largely unaddressed in Kenya's legal and normative frameworks.

\section{Bangladesh}

The 1947 Partition of India and then the war leading to Bangladesh's independence in 1972 produced huge population upheavals. Currently there are millions of Bangladeshis in India, many of whom have migrated from the environmentally fragile coastal areas in the southwest of the country as well as from the riverine communities affected by erosion. ${ }^{3}$ The presence of such groups is largely unacknowledged officially.

These events render population mobility a sensitive issue in national discourse. Despite widespread historical and current displacement, and the appearance of terms such as 'environmental refugees' or 'climate victims' in official Bangladeshi documents, Bangladesh has not acceded to the 1951 Convention, there is no legal definition of IDPs and the Guiding Principles have not been incorporated into domestic law.

Instead, government plans and policies dealing with the impacts of environmental change contain provision mainly for mitigation and post-disaster relief and recovery measures - material provision rather than more fundamental rights protection. The rights of people displaced or susceptible to displacement in the context of environmental stress and climate change are yet to gain explicit recognition in the legal and constitutional framework, and there is no machinery to define what rights those who are permanently displaced might expect and how these might be protected. Paradoxically maybe, past episodes of forced migration in the country have not resulted in a willingness to tackle issues of 'displacement' and 'displaced people' in a more profound manner.

\section{Vietnam}

The dominant contextual feature shaping Vietnam's national policymaking on the rights of groups displaced by environmental stress remains the dynamics surrounding the operation of its centrally planned economy. The establishment of Vietnam's socialist government in the 1970s not only reframed the political and economic organisation of the country but also entailed the relocation of approximately 6.7 million people (probably a significant underestimate) between 1976 and 1985 - with the regulation of migration continuing to be a core component of the centrally planned economy. Under such conditions there is no acceptance of individualised rights-based approaches, or a discourse on protection. The government has come to interpret 'displacement' as a reactive and uncontrolled process, in contrast to its proactive relocation strategies and regulated migration policies which relocated about 6.6 million people (about $8 \%$ of the population) between 2004 and 2009. There is no mention of displacement or resettlement in government policy documents, with the term 'relocation' being preferred and, accordingly, there is no scope to apply the Guiding Principles. The state's view on spontaneous, un-managed migration is reflected in the invisibility of unregistered migrants in the state system and therefore the question of rights does not arise.

Yet, migration in the country is expected to increase with the number of spontaneous migrants increasing significantly under growing environmental and economic pressures. In this context the government is implementing planned resettlement among a large number of households currently living in the most flood-prone parts of the Mekong delta. Thus, in Vietnam climate change appears to be mainstreamed as a developmental, but not a humanitarian, policy concern, certainly in comparison to the other case-study countries. With the scope for political engagement being so severely constrained in the country, the focus remains on providing material rights, to the exclusion of political ones.

\section{Ethiopia}

The Derg government (1976-91) used a major drought in the 1980s to justify large-scale, violent (in effect forced) resettlement strategies. 


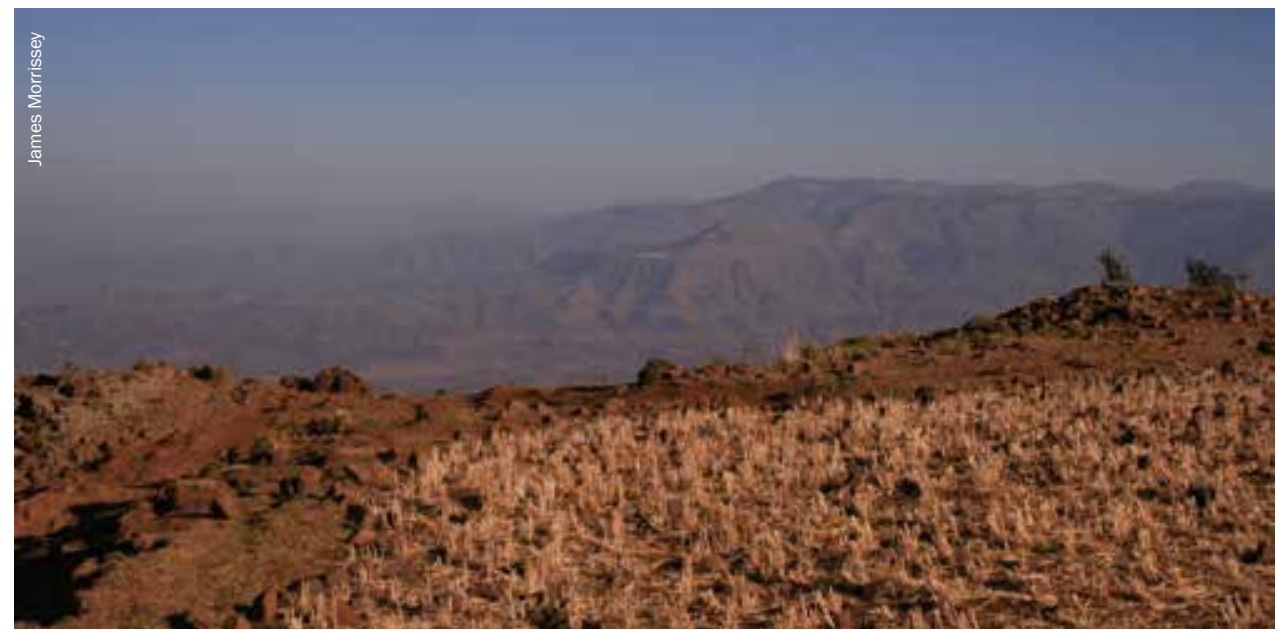

Adverse growing conditions in the Ethiopian highlands provide a context for framing development efforts exclusively in terms of material rights.

Since such strategies were principally aimed at countering the efforts of insurgent forces rather than securing livelihoods for individuals experiencing drought, the lasting impact has been to arouse popular suspicion of relocation programmes as a means to address environmental problems. As a result, the current government's approach is to focus on the provision of relief to environmentally stressed areas and on transforming livelihoods so as to reduce the imperative to move in the first place. Such efforts however have focused on the provision of material goods which have been tied to political compliance with what is, effectively, a one-party state.

The government does not use the term IDP and has not implemented the Guiding Principles. Although Ethiopia is a signatory to the Kampala Convention, the government has shied away from international agreements on human rights, which could be used as a benchmark of its failure to meet its obligations to its citizens and thereby undermine its claims to legitimacy. The positive elements of expanded social protection for, and efforts at ensuring the material wellbeing of, all migrants in Ethiopia - including those responding to environmental stress - should be viewed with caution; the institution of such material rights may well come at the expense of political rights.

\section{Ghana}

Ghana has a long history of hosting refugees from the region. During colonial times land expropriation and the resultant forced displacement and relocation of populations were significant. While there has been some episodic and small-scale refugee and 'forced' internal displacement in Ghana, present-day internal movement is strongly linked to colonial and postcolonial politico-historical determinants and has been absorbed into Ghana's social and economic fabric, thus rendering it far less politically sensitive than in the cases of Kenya and Ethiopia, for example. Accordingly it has limited political saliency.

The discourse in Ghana focuses on reconciling environmental pressures with socio-economic priorities in order to achieve sustainable goals of national development, rather than on population displacement. In this regard, Ghana too could be said to be adopting a developmental rather than a humanitarian response.

This is not to deny that the issue of migration itself is a pressing one. Rural to 
urban migration, farmer-herder conflicts in the transition zones, the displacement impacts of ecological degradation in the sub-Saharan north and tropical coastal south, and growing acknowledgement of the potential impacts of environmental stress and climate change on population mobility, are all present. Displacement 'induced by' environmental degradation in the northern regions of the country and the coastal belt are already showing up the emerging problem of whether the rights of those currently affected will be protected, and if so how.

However, migration and displacement issues are not yet linked to rights concerns and there is no rights protection architecture of norms and instruments dealing with population migration. In the case of people displaced by natural hazards and disasters, there are provisions under the 1996 National Disaster Management Act, which could, in principle, be extended in order to cover people displaced by slow-onset events such as climate change and thus invoking provisions of the National Disaster Management Organization. However, there is little evidence that Ghana seeks to implement norms set out in the Guiding Principles and it has signed but not ratified the Kampala Convention.

On the other hand, as a member of the Economic Community of West African States, it does accede to the regional migration initiatives which support relatively free population movement, a potentially significant mechanism as sub-Saharan environmental stress intensifies across the region.

\section{Conclusions}

Episodic migration histories, the complex political milieux within which migration sits and the unwillingness to engage with migration as an arena of public policy constitute both the backdrop to, and an explanation of, the reluctance of the governments to develop policy frameworks which would effectively tackle the current and future population displacement impacts associated with climate change and environmental stress.
Resistance to engaging with the politics of and policies for migration is underpinned by the reluctance of these countries - combined with different manifestations of weak governance structures - to address human rights issues. This is revealed in the reluctance in these case-study countries to develop legal and normative frameworks to protect the rights of migrants in general and specifically in relation to environmentally displaced people.

The protection of rights in the context of environmental stress is appropriated essentially in terms of material rights - for example restoration of livelihoods and resettlement to safer ground. This enables governments to acknowledge material needs whilst subverting the structural challenge of affording political rights - empowerment, decision-making and full participation in resettlement schemes, for example.

Given the enduring political denial of migration and displacement as a policy and social challenge, and the political fragility which mediates their disinclination to develop systematic and structural responses to the protection of rights, the prognosis for the protection of the rights of those displaced by changing environmental or climate conditions is poor. Analysis suggests that limited effort is likely to be put into adopting 'guiding principles' or, if adopted, little energy will be expended in implementing them. This problem is not easily resolvable in the climate change context.

Roger Zetter roger.zetter@qeh.ox.ac.uk is Emeritus Professor at the Refugee Studies Centre, University of Oxford. www.rsc.ox.ac.uk James Morrissey morrissey.james1@gmail.com was until recently a Research Officer at the Refugee Studies Centre.

The research on which this article is based was funded by the John D and Catherine T MacArthur Foundation.

1. www.idpguidingprinciples.org/

2. http://tinyurl.com/KampalaConvention

3. See articles by Siddiqui p21 and Bose p22. 